Editorial

www.mdpi.com/journal/catalysts

\title{
Metal Catalysts Recycling and Heterogeneous/Homogeneous Catalysis
}

\author{
Masahiko Arai ${ }^{1, *}$ and Fengyu Zhao ${ }^{2, *}$ \\ 1 Division of Chemical Process Engineering, Faculty of Engineering, Hokkaido University, \\ Hokkaido 060-8628, Japan \\ 2 Laboratory of Green Chemistry and Process, Changchun Institute of Applied Chemistry, Chinese \\ Academy of Sciences, China \\ * Authors to whom correspondence should be addressed; E-Mails: marai@eng.hokudai.ac.jp (M.A.); \\ zhaofy@ciac.ac.cn (F.Z.); Fax: +81-11-706-6594 (M.A.); +86-431-85261410 (F.Z.).
}

Academic Editor: Keith Hohn

Received: 18 May 2015 / Accepted: 20 May 2015 / Published: 27 May 2015

Heterogeneous metal catalysts rather than homogeneous ones are recommended for industrial applications after considering their performance in activity, separation, and recycling [1]. The recycling of metal catalysts is important from economic and environmental points of view. When supported and bulk metal catalysts are used in liquid-phase organic reactions, there is a possibility that active metal species are leaching away into the liquid phases [2,3]. The metal leaching would make it difficult for the catalysts to maintain their desired initial performance for repeated batch reactions and during continuous ones. The metal leaching would also cause some undesired contamination of products by the metal species dissolved in the reaction mixture, and the separation of the metal contaminants would be required to purify the products. Therefore, various novel methods have been proposed so far to immobilize/stabilize the active metal species and to separate/collect/reuse the dissolved metal species [4]. In addition, knowledge on the heterogeneous and homogeneous natures of organic reactions using heterogeneous catalysts is important to discuss their reaction mechanisms and catalytically working active species.

This Special Issue deals with the above-mentioned subject and contains interesting original and review articles on such organic synthetic reactions as $\mathrm{CO}_{2}$ conversion, biomass conversion, selective hydrogenation, $\mathrm{C}-\mathrm{C}$ coupling, and reductive amination reactions. The design of magnetic catalysts is one of the most efficient strategies for the synthesis of durable and reusable catalysts, which can be easily recovered by magnetic forces and recycled. Shokouhimehr [5] reviews the design, preparation, recyclability of various nanostructured magnetic catalysts for, in particular, the reduction of nitro aromatic 
compounds. Cheng et al. [6] report the promotional effect of $\mathrm{SnO}_{x}$ on the catalytic performance of $\mathrm{Ru} / \mathrm{Al}_{2} \mathrm{O}_{3}$ catalysts in the selective hydrogenation of $m$-dinitrobenzene to $m$-nitroaniline. They explain that electron transfer between active $\mathrm{Ru}$ species and $\mathrm{SnO}_{x}$ additives modifies the adsorption of the nitro group of the substrate, influencing the product selectivity, and also improves the stability of the catalysts. Li et al. [7] report the catalytic performance of phosphorus-doped $\mathrm{Ni} / \mathrm{Al}_{2} \mathrm{O}_{3}$ catalysts for the hydrogenolysis of a biomass-derived compound of glycerol. These are recyclable and selective catalysts for the production of 1 , 2-propanediol. The relative amounts of $\mathrm{Ni}$ and $\mathrm{NiO}$ species, which depend on the presence of a phosphorous dopant, are significant in determining the catalytic performance; a slight loss in activity occurs due to the deposition of carbonaceous materials on the catalyst surface. Ohtaka et al. [8] report that linear polystyrene-stabilized Pd nanoparticles are active and recyclable catalysts for a series of C-C coupling reactions in water. In these reactions, some Pd species leach and the dissolved Pd species are stabilized in the presence of tetrabutylammonium bromide and may participate in the catalytic processes. These Pd species may redeposit onto the polystyrene support and are recyclable even though a slight increase in the size of supported Pd particles occurs during the reaction. Ekbote et al. [9] report a polymer supported triphenylphosphine-palladium acetate complex catalyst for the indirect reductive amination of aldehydes. The catalyst is highly selective to the formation of the desired products and can be recovered and recycled without loss in the activity. Liu et al. [10] report a catalyst containing guanidine hydrochloride and $\mathrm{ZnI}_{2}$ for the environmentally benign synthesis of cyclic carbonates under mild reaction conditions. The catalyst gives a high yield of propylene carbonate and can be recycled, which is versatile for the cycloaddition of $\mathrm{CO}_{2}$ to other epoxides.

We would like to thank all authors who contributed to this Special Issue, as they have reported interesting results showing current progress in the design, preparation, and application of active, stable, and reusable heterogeneous catalysts. We are grateful to Professor Keith Hohn, Editor-in-Chief, for providing an honorable choice of guest editors and to Mary Fan and her staff in the Catalysts editorial office for their kind and patient cooperation with us.

\section{References}

1. Sheldon, R.A.; van Bekkum, H. Fine Chemicals through Heterogeneous Catalysis; Wiley-VCH: Weinheim, Germany, 2001.

2. Zhao, F.; Bhanage, B.M.; Shirai, M.; Arai, M. Heck Reactions of Iodobenzene and Methyl Acrylate with Conventional Supported Palladium Catalysts in the Presence of Organic and/or Inorganic Bases without Ligands. Chem. Eur. J. 2000, 6, 843-848.

3. Zhao, F.; Murakami, K.; Shirai, M.; Arai, M. Recyclable Homogeneous/Heterogeneous Catalytic Systems for Heck Reaction through Reversible Transfer of Palladium Species between Solvent and Support. J. Catal. 2000, 194, 479-483.

4. Bhanage, B.M.; Arai, M. Catalyst Product Separation Techniques in Heck Reaction. Catal. Rev. Sci. Eng. 2001, 43, 315-344.

5. Shokouhimehr, M. Magnetically Separable and Sustainable Nanostructured Catalysts for Heterogeneous Reduction of Nitroaromatics. Catalysts 2015, 5, 534-560.

6. Cheng, H.; Lin, W.; Li, X.; Zhang, C.; Zhao, F. Selective Hydrogenation of $m$-Dinitrobenzene to $m$-Nitroaniline over Ru-SnO ${ }_{x} / \mathrm{Al}_{2} \mathrm{O}_{3}$ Catalyst. Catalysts 2014, 4, 276-288. 
7. Li, X.; Cheng, H.; Liang, G.; He, L.; Lin, W.; Yu, Y.; Zhao, F. Effect of Phosphine Doping and the Surface Metal State of $\mathrm{Ni}$ on the Catalytic Performance of Ni/Al $\mathrm{O}_{3}$ Catalyst. Catalysts 2015, 5, 759-773.

8. Ohtaka, A.; Okagaki, T.; Hamasaka, G.; Uozumi, Y.; Shinagawa, T.; Shimomura, O.; Nomura, R. Application of "Boomerang" Linear Polystyrene-Stabilized Pd Nanoparticles to a Series of C-C Coupling Reactions in Water. Catalysts 2015, 5, 106-118.

9. Ekbote, S.S.; Gadge, S.T.; Bhanage, B.M. Polymer Supported Triphenylphosphine- Palladium Acetate Complex PS-TPP-Pd(OAc) $)_{2}$ as a Heterogeneous and Reusable Catalyst for Indirect Reductive Amination of Aldehydes. Catalysts 2014, 4, 289-298.

10. Liu, B.; Liu, M.; Liang, L.; Sun, J. Guanidine Hydrochloride/ZnI 2 as Heterogeneous Catalyst for Conversion of $\mathrm{CO}_{2}$ and Epoxides to Cyclic Carbonates under Mild Conditions. Catalysts 2015, 5, 119-130.

(C) 2015 by the authors; licensee MDPI, Basel, Switzerland. This article is an open access article distributed under the terms and conditions of the Creative Commons Attribution license (http://creativecommons.org/licenses/by/4.0/). 